\title{
Histórico sobre hérnias
}

\section{Background on hernias}

\author{
ECBC- MG Alcino Lázaro da Silva
}

$A$ s hérnias sempre foram uma tentação, sob o ponto de vista cirúrgico, porque são eternas. Enquanto houver um corpo humano, nas características em que nos apresentamos, existirá orifício natural por onde migram um ou mais tecidos vizinhos. A reflexão natural que fazemos é a de que todas as operações serão substituídas por avanços na área clínica, restando à cirurgia somente o trabalho nos orifícios e a correção de sequelas dos tratamentos no trauma e pós-oncoterapia.

Sendo uma área de meu interesse, desde os bancos escolares, frequentemente, fazemos reuniões alusivas aos seus problemas sob diversas formas didáticas. Há 23 anos realizamos um Congresso de Cirurgia Geral, no qual o assunto mais procurado é o de Hérnias. As salas se enchem. O salto natural foi, então, iniciar o movimento para a criação de uma Sociedade Nacional de Hérnias. Não foi difícil começar porque todo cirurgião geral e os egressos da formação inicial em cirurgia (especialistas) recebem, diagnosticam e operam hérnias menos complexas. Nos Congressos, então, ocorrem as mesas redondas e as palestras. Em sequência a essas atividades iniciamos algumas reuniões, com um grupo de colegas interessados, para a discussão sobre os problemas que a parede abdominal nos apresenta.

Em 2004, o fato que deu mais entusiasmo aos interessados em conhecer Hérnias foi a internacionalização do tema envolvendo os países: Brasil, México, Argentina, Alemanha e Itália.

Gepa ou Grupo de Estudo da Parede Abdominal foi o nome dado a esse primeiro ensaio. Atividade que agrupava colegas interessados na área de parede, destacando-se as Hérnias. Em setembro de 2006, no Hospital Sírio Libanês nos estendemos a outra atividade, agora maior, que denominamos "Gepal" - Grupo de Estudos da Parede Abdominal da América Latina.

A reunião foi discreta, em ambiente saudável, sem muita comida e sem bebida, mas com o espírito de "Café e Prosa", em que o simples supera o complexo bem como aparecem as diferenças de experiências e condutas. O café estimula a convivência e nos despoja de requisitos que impedem a criatividade (Figura 1).

A despeito de se ter iniciado o movimento para a criação da Sociedade Brasileira de Hérnias, no dia 28 de abril de 2007, num Congresso de "Cirurgia 2007", constituiu-se um plano de reuniões em torno das Hérnias.

Nas primeiras reuniões, nos Congressos de Cirurgia, compareceram vários colegas, a exemplo de Mânlio Basílio Speranzini, Renato Miranda de Melo, Cirênio de

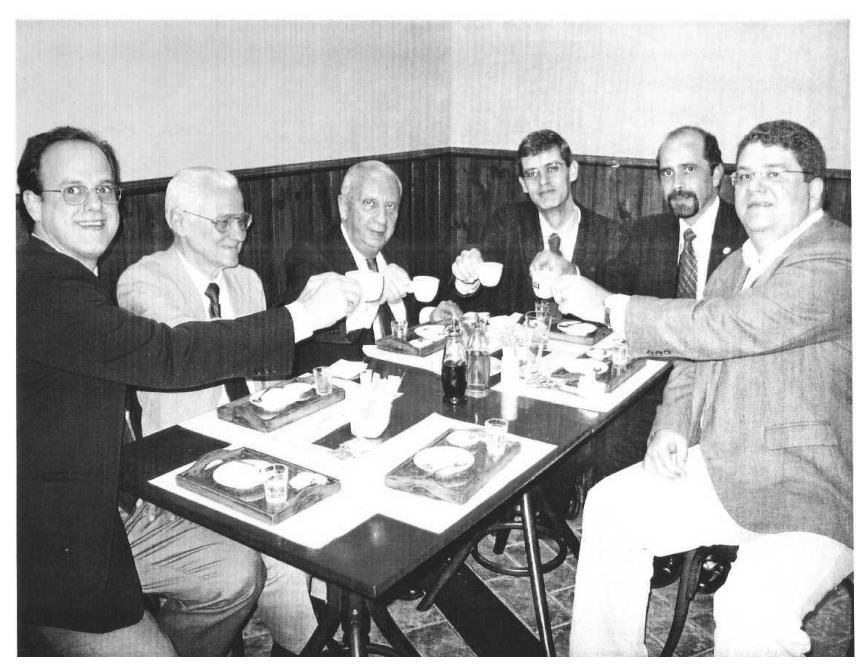

Figura 1 - Num cantinho discreto e respeitoso, um cafezinho foi o veículo que saudou a criação da Sociedade das Hérnias, vendo-se da esquerda para direita: Renato Miranda de Melo, Alcino Lázaro da Silva, Léon Herzage (Argentina), Ricardo Zugaib Abdalla, Juan Carlos Mayagostia González (México) e Claudio Renato P. de Luca Filho.

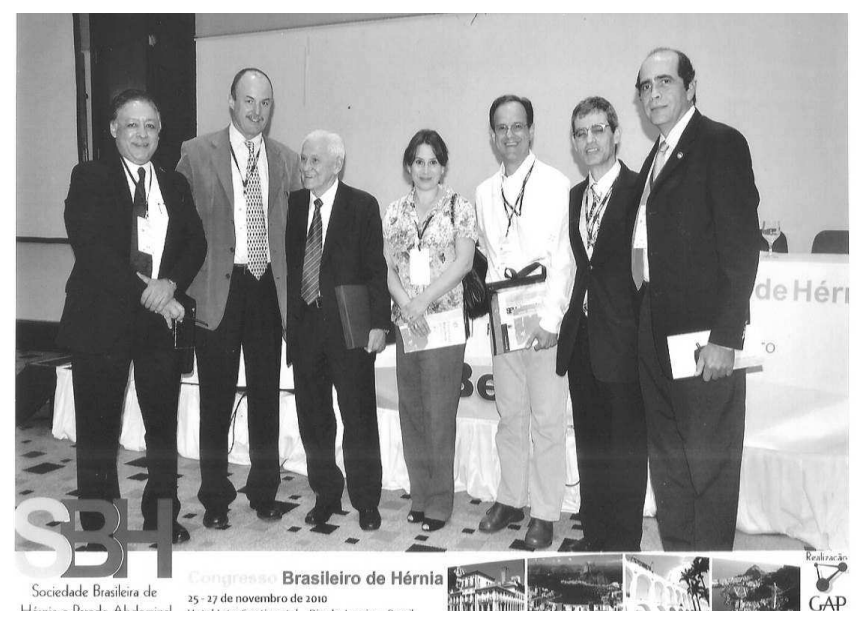

Figura 2 - Da esquerda para a direita vê-se colegas oriundos do México e Brasil, a saber Luíz Roberto Ramirez e Rigoberto Alvarez (México); Alcino Lázaro da Silva; Adriana Hernández (México); Renato Miranda Melo; Ricardo Zugaib Abdalla e Juan Carlos Mayagostia González (México). Não apareceram na foto os colegas Uve Klinge (Alemanha), Enrico Nicolo (Itália) e José Eduardo Ferreira Manso (Brasil).

Almeida Barbosa, Luiz Gonzaga Pimenta (" in memoriam"), Ricardo Zugaib Abdalla... Muitos outros colegas participaram de maneira descontínua por indisponibilidade com a data ou com os horários. Citamos alguns: Júlio César Beitler, 
Marcelo Lopes Furtado, Tereza Cristina Bernardo Fernandes, Manoel Roberto Maciel Trindade, Danilo Nagib Salomão Paulo, Albino Augusto Sorbello, Sérgio Roll, Flávio Malcher de Oliveira, Alvino Jorge Guerra, Álvaro Armando CarvaIho de Morais, Felix Andre Sanches Penhavel, José GuiIherme Minossi.

O fato histórico é que muitos cirurgiões no Brasil se preocupavam com o problema e o desenvolveram de forma a sempre discutir os desafios que a hérnia nos apresenta, a exemplo de Humberto Barreto, Carlos Ernani Rosado, Ary Lex.

A evolução para uma Sociedade foi irreversível porque há dados concretos: o cirurgião é o geral, a lesão é freqüente e ubiquitária, a solução pode ser dada em qualquer ambiente cirúrgico digno, o número é crescente pelo diagnóstico mais preciso e precoce e as iatrogenias, gerando hérnias, cresce ainda que lentamente após as laparotomias.
Os colegas foram se agrupando e se organizando e tornaram realidade, com ou sem participação de todos os cirurgiões gerais e herniólogos, a Sociedade Brasileira de Hérnia a partir de dezembro 2009, liderados por Flávio Malcher e Leandro Totti Cavazolla entre tantos Colegas famosos e experientes (Figura 2). A sede está localizada em Copacabana, Rio de Janeiro, sendo eleitos, naquela ocasião, presidente Ricardo Abdalla, vice-presidente Leandro Cavazzola e diretor executivo Flávio Malcher.

Se as iniciativas são ainda simples, sem aglutinação societária para todo o Brasil e para mais colegas que pretendem filiação, há duas realidades: a Sociedade está constituída, a matéria possui agora uma tribuna e a parede abdominal, tem guarida profissional e universitária e deve se estender, também, à atividade de pesquisa experimental.

Sigamos juntos e unidos em favor da Cirurgia 